\title{
METODOLOGIA DO ENSINO DE EDUCAÇÃO FÍSICA.
}

\author{
Aline Fabiane Barbieri
}

Metodologia de Ensino; Cultura Corporal; Ciclos de Escolarização. SOARES, C. L.; TAFFAREL, C. N. Z.; VARJAL, E; et al. São Paulo, Cortez, 1992.

O livro Metodologia do Ensino da Educação Física foi escrito por um grupo de autores de diferentes perspectivas teóricas com o objetivo de propor uma nova forma de trabalho com a Educação Física, bem como um novo modo de sistematização de conteúdos.

Apesar dessa heterogeneidade de perspectivas em que o livro foi desenvolvido, ele é, atualmente, a obra mais indicada para professores e estudantes das licenciaturas que pretendem direcionar seus trabalhos escolares em aproximação com a linha materialista histórica.

O primeiro capítulo tem como título A Educação Física no currículo escolar: desenvolvimento da aptidão física ou reflexão sobre a cultura corporal e é constituído por cinco subitens.

$1^{\circ}$ - A respeito do projeto político-pedagógico: os autores destacam que o texto trata de uma pedagogia emergente denominada de crítico-superadora e que essa tem três características específicas: é diagnóstica porque constata e lê os dados da realidade; é também judicativa, uma vez que julga essa constatação a partir de uma ética proveniente de interesses de determinada classe social e, por fim, é teleológica por que tem um objetivo específico. Assim, tendo em vista as determinações de classes o projeto políticopedagógico representa uma intenção, a qual o professor deve ter bem definida.

$2^{o}$ - Concepção de currículo ampliado: Nesse momento os autores destacam, principalmente, que o objeto do currículo é a reflexão do aluno, desenvolvendo sua capacidade intelectual. A função da escola seria apropriar-se do conhecimento científico dando-lhe um tratamento metodológico e confrontá-lo com a realidade social dos alunos. De acordo com a direção política adotada pela escola, constrói-se um eixo curricular que determina as disciplinas nucleares do currículo e a dinâmica curricular que é construída por três pilares: trato com o conhecimento, organização e normatização escolar.

$3^{o}$ - Alguns princípios curriculares no trato com o conhecimento: As disciplinas, os conhecimentos tratados em sala devem estar sempre vinculados à realidade social concreta do aluno, para que elas contribuam com a construção da identidade de classe deles.

Conexões: revista da Faculdade de Educação Física da UNICAMP, Campinas, v. 8, n. 1, p. 203-209, jan./abr. 2010. 
Os conteúdos, enquanto dados da realidade, devem ser apresentados de forma simultânea e espiralada, ressaltando sempre sua provisoriedade e historicidade, para que o aluno tenha sempre uma noção de totalidade do conhecimento.

$4^{\circ}$ - Ciclos de escolarização: Em detrimento ao modelo de seriação utilizado atualmente nas escolas, os autores apresentam uma nova forma de trato com os conteúdos por meio dos Ciclos de escolarização que se dividem em quatro:

O $1^{\circ}$ Ciclo de escolarização corresponde ao período da pré-escola até a $3^{\circ}$ série, sendo denominado ciclo de organização da identidade dos dados da realidade, onde os alunos formariam sistemas, encontrando relações entre as coisas, identificando suas semelhanças e diferenças. $\mathrm{O}$ aluno daria um salto qualitativo quando começasse a qualificar e associar objetos;

O $2^{\circ}$ Ciclo compreenderia o período da $4^{\circ}$ a $6^{\circ}$ série e é chamado de ciclo de iniciação à sistematização do conhecimento. Concluindo esse ciclo o aluno teria desenvolvido a capacidade de abstração, estabelecendo relações complexas entre as coisas. O salto qualitativo acontece nesse momento quando o aluno consegue estabelecer relações.

O $3^{\circ}$ Ciclo de escolarização iria da $7^{\circ}$ série à $8^{\circ}$ série sendo compreendido como ciclo de ampliação da sistematização do conhecimento. O aluno aqui desenvolveria a consciência da atividade teórica, consubstanciando um salto qualitativo quando se tornaria capaz de reorganizar a identificação dos dados da realidade através do pensamento teórico.

O último Ciclo seria do $1^{\circ}$ ao $3^{\circ}$ anos do Ensino Médio, e é chamado no livro de ciclo de aprofundamento da sistematização do conhecimento. $\mathrm{O}$ aluno desenvolveria aqui a capacidade de refletir sobre os objetos, dando um salto qualitativo quando conseguisse estabelecer relações entre eles.

Quanto a esses ciclos de escolarização, os autores afirmam que as séries são secundárias, sendo prioritária a aquisição do conhecimento pelo aluno.

$5^{\circ}$ - Confronto das perspectivas da Educação Escolar na dinâmica curricular: Nesse momento, Soares et al (1992) consideram que a tendência de desenvolvimento da aptidão física do homem tem 
contribuído historicamente para a defesa dos interesses burgueses. Em contrapartida, na perspectiva da reflexão sobre a cultura corporal busca-se desenvolver uma reflexão pedagógica sobre os conhecimentos socialmente produzidos e historicamente acumulados pela humanidade. Essa perspectiva entende que a dimensão corpórea do homem se materializa nas três atividades produtivas da história da humanidade: na linguagem, trabalho e poder. Logo, o conhecimento escolar seria tratado desde sua gênese, permitindo ao aluno entender-se como sujeito histórico capaz de interferir na sociedade. $\mathrm{Na}$ escola essa perspectiva de Educação Física pode contribuir para os interesses populares, substituindo a individualidade pela solidariedade, a disputa pela cooperação, enfim. Nesse processo os autores destacam a grande importância da presença da técnica e da tática no processo de ensino/aprendizagem. A observação realizada é referente à limitação que o professor vem dando em suas aulas à técnica e a tática, ou seja, de acordo com esta nova abordagem de trabalho da educação física a técnica não deve ser vista como objetivo, como fim, mas sim, como meio para proporcionar o desenvolvimento completo do aluno.

O segundo capítulo da obra é denominado Educação Física Escolar: na direção da construção de uma nova sintese, e os autores o iniciam apresentando a definição de educação física como sendo uma prática pedagógica que, em âmbito escolar, tematiza formas de atividades expressivas corporais como o jogo, esportes, dança, ginástica, formas estas que configuram uma área de conhecimento denominada de cultura corporal. Em seguida, com o objetivo de facilitar o entendimento da historicidade da educação física, é apresentado um breve histórico dessa prática pedagógica.

Metodologia do Ensino da Educação Física: a questão da organização do conhecimento e sua abordagem metodológica é o título do $3^{\circ}$ capítulo. Sobre a metodologia do trabalho com os conteúdos da cultura corporal, Soares et al (1992) consideram a importância da problematização relacionada com contexto sócio-cultural do aluno, como estratégia para a otimização da transmissão dos conteúdos escolares da educação física. Nessa perspectiva, os autores entendem que só se fazem legítimos nos espaços escolares os conteúdos trabalhados de forma que proporcione ao aluno uma leitura históricocrítica de sua realidade social, ou seja, conteúdos que sejam devidamente historicizados e contextualizados que capacitem os alunos a fazerem relações dos conceitos e mediações trabalhadas em aula com as contradições sociais vigentes.

Num segundo momento, o capítulo aborda aspectos relacionados a organização e a sistematização dos conteúdos, devendo estes, de acordo com os autores, estarem distribuídos dentro de um tempo Conexões: revista da Faculdade de Educação Física da UNICAMP, Campinas, v. 8, n. 1, p. 203-209, jan./abr. 2010. 


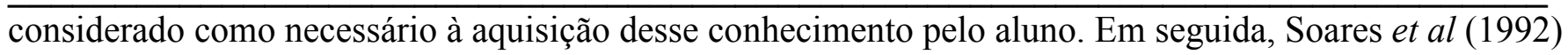
exemplificam formas de distribuição de conteúdos nesses ciclos de escolarização propostos por meio dos temas: jogos, esporte, ginástica e dança.

O último capítulo chama-se: Avaliação do Processo Ensino-Aprendizagem em Educação Física, e nele se destaca que as avaliações em educação física têm sido direcionadas por um único referencial, denominado aqui de "paradigma docimológico clássico". Assim, têm sido enfatizadas avaliações com fins classificatórios e seletivos, que acabam por discriminar e contribuir para a evasão escolar da classe trabalhadora. É importante destacar também que os processos avaliativos são determinados pelas teorias pedagógicas, que por sua vez, são frutos de necessidades sociais concretas. Nesse sentido, essa atual forma avaliativa é resultante de necessidades da organização social capitalista. Essa atual forma avaliativa, pautada no desenvolvimento da aptidão física, busca identificar nas escolas os talentos esportivos. Nesse espaço, o esporte toma lugar de destaque, negligenciando o trabalho com os elementos da cultura corporal, dando as aulas, de acordo com Soares et al (1992), um significado meritocrático, uma vez que valoriza, sobretudo, o esforço individual.

No processo de ensino-aprendizagem, os teste e medidas não trazem aos alunos suas evoluções qualitativas, somente as quantitativas.

A proposta de avaliação do processo de ensino-aprendizagem de educação física apresentado no livro leva em conta alguns aspectos, dentro dos quais destacam-se:

O projeto histórico: Deve-se ter em mente em qual sociedade estamos inseridos e qual sociedade que queremos construir;

As condutas humanas: A proposta de avaliação do processo de ensino-aprendizagem deve levar em conta a observação, a análise e conceituação de elementos que compõem a totalidade da conduta humana que se expressam no desenvolvimento das atividades.

As práticas avaliativas: Se mostra como indispensável a substituição de práticas avaliativas mecânicas (testes e medidas, por exemplo) por práticas produtivo-criativas para que o processo de avaliação auxilie na identificação dos conflitos do processo de ensino-aprendizagem para a superação dos mesmos por meio de esforço crítico e criativo dos alunos. 
As decisões em conjunto: Os alunos devem ter espaço para participarem do processo de avaliação, eles devem ter a oportunidade de expressarem seus objetivos de ação.

O tempo pedagogicamente necessário para a aprendizagem: No processo de ensino-aprendizagem um tempo deve ser destinado para a transmissão e assimilação de conhecimentos para o aluno, sempre respeitando seu ritmo de aprendizagem, por meio, principalmente, da problematização.

A compreensão crítica da realidade: Deve-se romper com o pensamento idealista de que todos os alunos são iguais (seres puramente biológicos) e inseridos numa sociedade natural, dando lugar a estratégias de ensino que desenvolvam nos alunos uma leitura crítica da realidade, para ampliar e aprofundar a compreensão deles a cerca da sociedade e seus determinantes.

\section{CONSIDERAÇÕES SOBRE A OBRA:}

Durante a leitura e análise do texto apresentado, surgiram alguns pontos que acredito que sejam merecedores de destaque no sentido de estarmos os repensando sob a perspectiva crítica, sempre com o objetivo de realizarmos uma maior reflexão e, talvez, uma superação destes, que se seguem:

-“Escola que se pretende democrática, universal, gratuita, obrigatória, laica e unitária, resultado de um projeto coletivo e adequado em relação aos seus equipamentos materiais e espaços físicos” (p. 23).

Sobre o termo democracia, é importante analisar o texto de Coutinho (2002) ${ }^{1}$ intitulado A democracia na batalha das idéias e nas lutas politicas do Brasil de hoje, pois se mostra como bastante interessante no sentido de entender o real significado de democracia e, consequentemente, sua ligação com interesses sociais conservadores. Nesse sentido, objetivar uma escola democrática, como apresentado no fragmento acima, explicita uma visão diferente da materialista histórica.

-"Contemporaneamente pode-se afirmar que a dimensão corpórea do homem se materializa nas três atividades produtivas da história da humanidade: linguagem, trabalho e poder" (p. 39).

-“A expectativa da Educação Física escolar, que tem como objetivo a reflexão sobre a cultura corporal, contribui para a afirmação dos interesses de classe das camadas populares, na medida em que desenvolve uma reflexão pedagógica sobre valores como solidariedade substituindo individualismo,

\footnotetext{
1 COUTINHO, Carlos Nelson. A democracia na batalha das idéias e nas lutas políticas do Brasil de hoje. In: FÁVERO, Osmar; SEMERARO, Giovanni (orgs). Democracia e construção do público no pensamento educacional brasileiro. 2. ed. Petrópolis: Vozes, 2002, p. 11-39.
}

Conexões: revista da Faculdade de Educação Física da UNICAMP, Campinas, v. 8, n. 1, p. 203-209, jan./abr. 2010. 
cooperação confrontando a disputa, distribuição em confronto com a apropriação, sobretudo enfatizando a liberdade de expressão dos movimentos-a emancipação-, negando a dominação e submissão do homem pelo homem" (p. 40).

Nesse momento, é importante destacar que contribuir para a afirmação dos interesses de classe das camadas populares transcende a simples substituição de valores individuais para os de solidariedade e cooperação. A educação física em âmbito escolar deve contribuir para a afirmação dos interesses populares na medida em que trata de conhecimentos historicamente produzidos e acumulados de forma crítica para que o aluno seja capaz de identificar as contradições sociais e se identificar como sujeito produto e produtor histórico-social.

-"Esse movimento que orienta a ação revolucionária dos homens comporta alguns momentos simultâneos, conforme menciona Chaú:

DESESTABILIZAR, ESTRUTURAR, CONVENCER, CONSOLIDAR concepções práticas e ideológicas que delimitam o contexto sócio-histórico, confrontando-as com outras que a elas se opõem, buscando competência e objetividade para levar à frente este projeto de forma a materializá-lo, explicitando assim a conquista de uma outra qualidade de vida para os homens, entendidos enquanto sujeitos históricos e construtores de seu próprio processo de humanização" (p. 43).

Acredito que o termo convencer deva ser repensado, pois, talvez, fuja do entendimento de transmissão e aquisição de conhecimento de forma crítica, refletida e emancipatória, própria da perspectiva críticosuperadora. Isso faz com que os sujeitos se distanciem do entendimento de que os protagonistas do diálogo se relacionam dialeticamente de acordo com as necessidades sócio-históricas de cada um.

Esses pontos foram apenas alguns dos que poderiam compor este texto, tendo em vista que a necessidade de superar algumas considerações presentes nele é evidente. Para uma construção de informações mais concretas sobre o livro e a metodologia faz-se necessário, no entanto, uma análise mais completa e melhor fundamentada. 
RESENHA

ALINE FABIANE BARBIERI

Universidade Estadual de Maringá

Acadêmica do 3 ano de Educação Física Licenciatura pela Universidade Estadual de Maringá (UEMPR). 